\title{
Pandemia, as reinvenções educacionais e o mal-estar docente: uma contribuição sob a ótica psicanalítica
}

\author{
Pandemic, educational reinventions and teacher malaise: a contribution \\ from a psychoanalytical perspective
}

\author{
iD Michel Douglas Pachiega \\ Mestrando em Educação Sexual na Universidade Estadual Paulista \\ "Júlio de Mesquita Filho", Araraquara - São Paulo, Brasil. \\ Graduado em Psicologia pela Universidade Anhembi-Morumbi, São Paulo, SP. \\ michel.pachiega@gmail.com
}

(iD) Débora Raquel da Costa Milani Doutorado e Mestrado em Educação Escolar pela Universidade Estadual Paulista "Júlio de Mesquita Filho" - UNESP-FCLAr em Araraquara, São Paulo - Brasil. deb.milani@yahoo.com.br

Resumo: A pandemia causada pela Covid-19 impôs ao sistema educacional muitos ajustes e alterações e, com isso, trouxe aos educadores novas formas de adaptação, gerando sofrimento mental e físico. Diante disso, a partir da psicanálise, este trabalho visa refletir sobre o mal-estar docente e seus sintomas frente às mudanças da prática pedagógica durante a pandemia. Para tanto, utilizamos a pesquisa teórica para compor as reflexões aqui apresentadas, haja vista pesquisas anteriores já terem demonstrado que o mal-estar e seus sintomas estão presentes, em maior ou menor grau, na vida de educadores. Concluímos que é necessário repensar as formas das relações transferenciais entre aluno-professor, refletir sobre o papel do sujeito-suposto-saber e rever as condições em que a Educação pode ser praticada, ampliando as possibilidades docentes concernentes às tecnologias, à quebra de paradigma e às inovações educacionais do século 21. Após a pandemia e em pesquisas posteriores é importante a ampliação dessa temática.

Palavras-chave: Educação. Mal-estar docente. Pandemia. Psicanálise.

Abstract: The pandemic caused by the new coronavirus imposed many adjustments and changes to the educational system and, with this, brought to educators new forms of adaptation, generating mental and physical suffering. Therefore, based on psychoanalysis, this work aims to reflect on teacher malaise and its symptoms in the face of changes in pedagogical practice during the pandemic. For this, we used theoretical research to compose the reflections presented here, since previous research have shown that malaise and its symptoms are present, to a greater or lesser extent, in the lives of educators. We conclude that, it is necessary to rethink the forms of transferential relations between student-teacher, reflect on the role of the subject-supposed-toknow and review the conditions with which Education can be practiced, expanding the teaching possibilities with regard to technologies, breaking paradigm and educational innovations of the $21 \mathrm{st}$ century. After the pandemic and in subsequent research, it is necessary to expand this theme.

Keywords: Education. Teacher malaise. Pandemic. Psychoanalysis. 


\section{Introdução}

As questões de ensino e aprendizagem perpassam vários âmbitos da vida do aluno, do professor e da comunidade escolar. A saúde mental e emocional de discentes e docentes necessita de equilíbrio e adequações para que o ensino e a aprendizagem aconteçam com fluidez.

Desde antes da Covid-19, pesquisas como as de Andrade e Cardoso (2012), Diehl e Marin (2016), Tostes et al. (2018) indicam que educadores brasileiros passam por alterações comportamentais e emocionais durante a prática docente, chegando aos limites da psicopatologia e do adoecer, principalmente nos diagnósticos de estresse, ansiedade e síndrome de burnout. Mas foi a partir do dia 11 de março, data do anúncio oficial proferido pela Organização Mundial de Saúde - OMS (2020), que a doença causada pelo novo coronavírus foi caracterizada como uma pandemia. Em nível mundial, os professores precisaram se reinventar e, em um curto período de tempo, incorporar as tecnologias da informação e da comunicação, além de todas as adaptações pedagógicas necessárias para que as aulas remotas pudessem acontecer.

De acordo com a Organização das Nações Unidas para a Educação, Ciência e Cultura UNESCO (2020), a crise provocada pela Covid-19 causou a suspensão das aulas em escolas e universidades, afetando mais de 90 por cento dos alunos do mundo. Nesse momento, as formas de trabalho do docente e das instituições educacionais foram sendo revistas, renovadas, alteradas e, sobretudo, repensadas sob a ótica dos padrões até então praticados. Tais alterações são confirmadas pela pesquisa "Educação, Docência e COVID-19”, realizada com o apoio do Instituto de Estudos Avançados da Universidade de São Paulo - USP e da USP Cidades Globais, na qual os autores fazem um levantamento da Educação no Brasil e no Estado de São Paulo, e asseveram que

Desde março de 2020, cerca de 48 milhões de estudantes deixaram de frequentar as atividades presenciais nas mais de 180 mil escolas de Ensino Básico espalhadas pelo Brasil como forma de prevenção à propagação do coronavírus (INEP, 2019). Desse total, a Rede Estadual de Educação de São Paulo, a maior do país, abrange cerca de 3,8 milhões de matrículas e cerca de 200 mil educadores e educadoras. (GRANDISOLI; JACOBI; MARCHINI, 2020, p. 1).

Silva et al. (2020) esclarecem que, durante a pandemia no Brasil, "por não conseguir atingir os objetivos propostos pela instituição, e devido às diversas pressões relacionadas ao manuseio das tecnologias, gravações de aulas, os docentes acabam adoecendo". No âmbito internacional, segundo Araújo et al. (2020), as pesquisas revelam que as formas do adoecer docente são vividas por meio da manifestação de níveis elevados de ansiedade, humor deprimido, aparecimento de várias formas de sintomas do estresse e incertezas recorrentes, que levam os profissionais ao esgotamento mental e profissional. 
$\mathrm{Na}$ psicanálise, o termo mal-estar é utilizado quando se refere ao adoecimento psíquico. Freud (1930/1996) em O mal-estar na civilização, empenha-se em explicar o mal-estar e argumenta que essa forma humana de sofrer sobrevém das relações e vivências intersubjetivas e da influência recebida do mundo externo, principalmente daquelas sobre as quais não temos controle algum. Para o psicanalista, o termo "mal-estar na civilização" refere-se às condições necessárias à construção e manutenção do processo civilizatório, pois exige que os sujeitos abram mão da satisfação pessoal pelo bem-estar comum, o que traz desconforto e dor.

No que diz respeito ao momento atual da prática docente, o mal-estar docente é inteiramente ligado às novas formas de relações da prática pedagógica, à identidade docente e às novas demandas do mundo externo que não estão sob o controle de professores e alunos. Confirmando esse ponto de vista, Esteve (1999, p. 57), descreve o mal-estar docente como "um conjunto de consequências negativas que afetariam o professor a partir da ação combinada das condições psicológicas e sociais em que se exerce a docência”.

A atualidade revela e aponta os novos rumos e desafios dos engajados nas tarefas educacionais, que, sob um olhar mais amplo, consideram o ato de ensinar impossível. Parece haver falta de esperança, intenso trabalho, altos níveis de estresse e, sobretudo, evidente descaso e falta de apoio social, político e cultural, o que frustra grande parte dos professores, que, por vezes, dizem que se sentem sobrecarregados, adoentados e em sofrimento (LEITE; SOUZA, 2007).

Esteve (1995) aborda algumas consequências mais evidentes e presentes do mal-estar docente, a saber: sentimentos de desajustamento, desejos manifestos ou velados de abandonar a docência, esgotamento, angústia, estresse, autodepreciação, depressão, ansiedade, entre outras. Diante disso, torna-se urgente pensar e repensar as formas de ensino e aprendizagem - presencial, híbrida ou remota - para que docentes e alunos não venham a intensificar, de maneira negativa, as questões de saúde mental e mal-estar.

\section{Metodologia}

Para abarcar os questionamentos deste trabalho e refletir sobre o modo como o olhar psicanalítico pode se apropriar dos processos educacionais e de suas possibilidades e explicá-los perante a pandemia, que está alterando a lógica do funcionamento da sociedade e concomitantemente da escola, embasamo-nos no arcabouço teórico da psicanálise. Isso implica pensar a saúde mental do educador diante do ensino remoto e das condições de trabalho impostas neste ano letivo de 2020. 
A pesquisa teórica mostra-se importante para a produção científica quando se faz presente em situações atuais e levanta questionamentos necessários à discussão e à problematização, levando a ciência, a partir dos conceitos, a resultados e possibilidades de resolução. De acordo com Maldonado (2011, p. 294-295),

A pesquisa teórica não pode ser reduzida a mera revisão literária para ser editada em resenhas rápidas repetitivas; pelo contrário, exige a problematização constante das ideias e dos raciocínios as questões e os aspectos do problema/objeto em fabricação.

Além disso, visando destacar a relevância da pesquisa teórica com base na psicanálise, Lameira, Costa e Rodrigues (2017, p. 76) afirmam

[...] que o trabalho teórico na perspectiva psicanalítica não se confunde com o trabalho teórico de outros métodos de pesquisa estabelecidos no meio acadêmico. [...] Se por um lado podemos dizer que a prática só pode avançar com o trabalho conceitual, por outro, vemos que a práxis continuamente esburaca esse saber teórico que só pode ser tomado na perspectiva de uma contínua abertura à revisão.

Em vista disso, nossa busca por produções e pesquisas ocorreram por meio de contínuas consultas a bases de dados e portais - BVS-PSi, PubMed, SciELO e Google Scholar, LILACS, Index Psi, PePSIC, Educ@ -, distribuídas em diferentes dias dos meses de agosto e setembro de 2020, com o uso de descritores como: "coronavírus", "COVID-19”, "saúde mental do educador", "mal-estar docente”, "educação", "educação and psicanálise” e "pandemia”. As pesquisas também se estenderam a outros sítios de organizações ligadas às áreas da Educação, da Saúde e da Psicanálise, com o propósito de buscar os desenvolvimentos mais recentes ligados à COVID-19, à prática docente e ao adoecimento do educador.

Todavia, embora os descritores ora considerados propiciem ampla possibilidade de busca, ainda não foi possível encontrar produções diversas sobre o tema principal deste trabalho: saúde mental do professor ante a pandemia, sob o olhar psicanalítico. Por isso, como relatado anteriormente, é necessário ampliar o olhar sobre a saúde do professor e as possibilidades da prática docente com mais estabilidade emocional e mental.

Ao mesmo tempo, como este trabalho apresenta limitações em razão de não ser uma pesquisa empírica, feita entre educadores de algumas ou de específicas regiões do país, a ele podem ser agregadas pesquisas futuras sobre as várias "educações" que temos pelo Brasil, com suas especificidades e (im)possibilidades. 


\section{Educação e psicanálise}

Desde os primórdios dos estudos psicanalíticos, a relação entre psicanálise e educação tem pontos de entrelaçamento e discordâncias, e, conforme teóricos como Santiago (2008), Kupfer (2005) e Mariane Ribeiro (2006), o modo dinâmico de entender as questões de ensino e aprendizagem revela-se a partir dos conceitos de transferência e de sujeito-suposto-saber, que permeiam as práticas docentes.

Na construção teórica psicanalítica, Freud (1912/2010) descreve o processo transferencial como um movimento dinâmico que combina aspectos inatos agregados às vivências individuais e subjetivas do indivíduo. Essa soma molda a vida do sujeito, estruturando formas de se relacionar com o outro e amar durante todo o ciclo vital, bem como condições para que isso aconteça. Para Freud, a transferência ocorre de maneira erótica, positiva ou negativa, funcionando, normalmente, de forma combinada à diversa gama de sentimentos que as relações comportam.

Diante disso, podemos dizer que a transferência envolve afeto, sendo vivenciada, positivamente, por admiração e consideração, ou negativamente, por hostilidade. Nesse sentido, embora a teoria tenha sido proposta a partir da relação analista-paciente, como envolve toda e qualquer relação do sujeito, também está presente na relação aluno-professor. E qual a relação entre transferência e sujeito-suposto-saber na prática docente? Para Lacan (1988/1964, p. 220) "desde que haja em algum lugar o sujeito-suposto-saber [...] há transferência".

Isso quer dizer que o professor é concebido, de uma forma substitutiva, como alguém da experiência de vida do aluno tal qual o pai, a mãe, o cuidador, o tio, etc. Essa substituição é carregada de afetos e sentimentos da história de vida do aluno, estruturando sua relação com o professor como positiva ou negativa, amável ou hostil. Em outras palavras, ora o professor é odiado, ora amado.

Durante esse período de aulas online, o professor que se apropriou desse papel de sujeitosuposto-saber, na relação transferencial com o aluno, pode ter perdido essa função de detentor do saber a ser transmitido inerente a esse papel social e outrora introjetada como parte de sua personalidade e identidade profissional. De acordo com Carvalho e Vasques (2016, p. 5),

\footnotetext{
Mudanças emocionais estão no centro dos problemas deste século, no qual inclusive as crianças são os sintomas de suas famílias. Uma das soluções para essa relação que parece estar destoada é a utilização de um manejo diferente do professor em sala de aula onde o docente passa a ouvir mais o que seu aluno traz para o contexto escolar se fazendo de mediador destes conflitos e, se faz necessário a formação do docente trazendo uma mudança que irá beneficiar a área educacional através do manejo diferenciado no relacionamento.
} 
Assim, com base na importância de perceber e refletir sobre as formas educativas, Mariane Vieira Machado Ribeiro (2006) reforça a relevância da relação entre Psicanálise e Educação, que se dá como um aporte teórico, no caso da primeira, e como uma construção social, no caso da segunda, ambas afetando, simultaneamente, o desenvolvimento da outra com o passar das décadas.

Tal construção dá-se pelo fato de que essas duas áreas remetem às questões do desenvolvimento do homem e da sociedade. Ao longo de sua obra, Freud (1908/1976a), alterou seu posicionamento sobre a função da Educação. Inicialmente, retratou críticas com relação ao modo como a Educação reprime a sexualidade, resultando na neurose e nos sintomas de inibição do indivíduo. Muitos anos depois, ele passou acreditar que medidas preventivas nessa área deveriam ser tomadas, por meio da formação do professor em psicanálise e da análise pessoal de suas práticas pedagógicas (FREUD, 1932/1976b). Em seus últimos textos, a ideia de que a Educação poderia ter medidas preventivas não prevaleceu, visto concluir que ela estava entre as profissões impossíveis como governar e curar (FREUD, 1937/1976c).

No entendimento de Kupfer (2005) é a partir da Educação que o controle do princípio do prazer é feito para uma melhor adaptação à realidade, reconhecendo sua participação ativa e positiva no desenvolvimento humano. Em contraponto com essa ideia, Filloux (2002) considera que as funções da Educação e da Psicanálise se desdobram em oposições: a primeira sendo uma dinâmica educativa e a segunda, terapêutica.

Tais dinâmicas apresentam-se a partir da linguagem - docente e discente -, no ambiente escolar e acadêmico, seja ele físico ou virtual. Nesse aspecto, Lacan (1992), teórico da psicanálise com forte influência freudiana, propõe estudar o campo da linguagem, que é o meio pelo qual o homem é humanizado. Em outros termos, é um outro que confirma a palavra para que o humano se subjetive em sua maneira mais pura, com o intuito de adquirir um saber. Na Educação, essa aquisição é mediada pelo professor e o ensino não acontece sem a presença de ambos - aluno e professor.

Outro detalhe importante na relação dinâmica dos processos de ensino e aprendizagem é descrito por Salzberger-Wittenberg, Henry e Osborn (1990), quando destacam a relevância dos componentes emocionais nas condições de aprendizagem e afirmam que há uma íntima relação entre adoecimento mental e aprendizagem. Diante disso, perguntamos: como será que estão as emoções de professores e educadores nesse período em que o mundo educacional mudou de maneira compulsória?

Conforme Vasconcelos e Miranda (2012, p. 2), 
Ensinar tornou-se penoso e há uma angústia por não saber fazê-lo atualmente. Estes professores parecem anunciar um descompasso entre suas concepções, valores e representações acerca do ensinar - elaboradas no decorrer da carreira - em relação aos estudantes com os quais atuam.

É possível observar, de acordo com os autores, que a Educação ocorre a partir da relação professor-aluno; relação descrita pela Psicanálise como transferência. Sobre o conceito de transferência, Márden de Pádua Ribeiro (2014, p. 25) relata que

[...] trata-se de um fenômeno que é percebido em todas as relações humanas. [...] pode se instalar e produzir efeitos reparáveis, tanto positivos quanto negativos. É um fenômeno constante, presente em todas as relações, sejam profissionais, hierarquizadas, amorosas. A transferência pode ser entendida como reedições de vivências psíquicas que são atualizadas em relação à pessoa do analista e, no caso específico, atualizado em relação à figura do professor.

Ratificando esta ideia de que, na escola, a transferência propicia a aprendizagem, Santos (2009) relata que é na relação aluno-professor que ela ganha vida e, com isso, pode ressignificar afetos, até mesmo os mais profundos e inconscientes. Nesse mesmo contexto, em uma de suas reflexões acerca da Educação, Freud (1914/1969, p. 248) assevera: “é difícil dizer se o que exerceu mais influência sobre nós e teve importância maior foi a nossa preocupação pelas ciências que nos eram ensinadas ou a personalidade de nossos mestres".

Kupfer (2005, p. 91) retoma essa condição essencial do aprendizado ao dizer que a transferência se coloca no sistema ensino e aprendizagem e "se produz quando o desejo de saber do aluno se aferra a um elemento particular, que é a pessoa do professor".

Durante a pandemia, quando as aulas estão ocorrendo de forma virtual, com menos contato aluno-professor, com partes das atividades sendo desenvolvidas e acompanhadas por pais, mães e/ou cuidadores, as questões narcísicas do professor podem estar abaladas. A psicanálise relata que o educador, para obter resultados positivos, necessita declinar da posição de sujeito detentor de todo o saber, facilitando o trabalho do aluno de lidar com as frustrações do próprio professor ao não corresponder às suas expectativas e com isso, ressignificar os resquícios da infância, abrindo caminho para a aprendizagem (KUPFER, 2005; SANTOS, 2009).

Para Márden Ribeiro (2014, p. 28),

[...] a grande angústia provocada pela Psicanálise seja justamente negar as fórmulas prontas disponibilizadas aos professores, que em muitas ocasiões servem principalmente para tentar impedir algo de inusitado, que quebra o esperado pelo professor no seu planejamento de aula, provocando desconforto e angústia para o professor no ambiente de sala de aula.

Nesse aspecto, é interessante refletir sobre o adoecimento do professor durante a pandemia como uma renúncia compulsória de um eu idealizado e de uma posição do sujeito-suposto-saber. 
Soma-se a esses dois fatores, neste momento de aulas remotas, a existência de possíveis falhas na relação aluno-professor, como os abalos que podem acontecer nas questões transferenciais e, com isso, impossibilitar o professor de realizar a prática docente completa, como propõe a Psicanálise. Além disso, outros fatores podem contribuir para o mal-estar docente, como o lidar com a tecnologia, a distância física dos alunos e do ambiente escolar, as inovações pedagógicas e as adaptações didáticas, além de tantos outros fatores adjacentes a essas mudanças.

\section{O mal-estar docente, prática pedagógica e a pandemia}

Inicialmente, cabe, aqui, colocar alguns questionamentos. Durante a pandemia, de que maneira a relação aluno-professor acontece nas formas de ensino-aprendizagem online? É possível pensar que as questões de transferência e sujeito-suposto-saber são viáveis no ensino remoto? Se as adaptações tecnológicas e educacionais indicam um adoecimento docente, o que fazer para minimizar tais efeitos? Será que os componentes da transferência estão em movimento no ensino remoto?

Pode ser que tais questionamentos não sejam respondidos e clarificados momentaneamente, mas já é possível refletir sobre alguns pontos.

Antes mesmo da pandemia, as questões de saúde-doença e os sintomas apresentados pelos professores foram foco de pesquisa, de preocupação e também de motivação para a ampliação de políticas públicas voltadas à docência e aos modos de adoecimento. Murta (2001) descreve aspectos do sofrimento psíquico no magistério e reafirma a ideia de que tais condições são causas de afastamento da sala de aula e, em certo grau, definitivamente do ambiente escolar.

Ante a pandemia, é propício utilizar o conceito de mal-estar docente, proposto por Esteve (1999, p. 97), que o descreve como "um conceito da literatura pedagógica que pretende resumir o conjunto de reações dos professores como grupo profissional desajustado devido à mudança social". Ainda segundo o autor,

A expressão mal-estar docente (malaise enseignant, teacher burnout) emprega-se para descrever os efeitos permanentes, de caráter negativo que afetam a personalidade do professor como resultado das condições psicológicas e sociais em que exerce a docência, devido à mudança social acelerada. (ESTEVE, 1999, p. 98, grifos do autor).

Em 2020, algumas pesquisas (CARVALHO et al., 2020; WANG et al., 2020; ASMUNDSON; TAYLOR, 2020; BROOKS et al., 2020) já identificaram aspectos relativos à saúde mental que estão evidentes na população em geral, sendo eles: confusão, raiva, casos de suicídio, depressão, ansiedade e níveis elevados de estresse. 
Ligadas aos sintomas de ansiedade e estresse, pesquisas recentes (ALDWIN, 2009; COMPAS et al., 2001; LAZARUS; FOLKMAN, 1984) levam em consideração indicadores mais comuns de ordem física, emocional, comportamental e cognitiva como cefaleia, taquicardia, alterações no sono e no apetite, humor deprimido, volição alterada, aumento da agressividade e do uso de substâncias, dificuldade na tomada de decisão, alteração da atenção e da memória, limitações na concentração. Sendo indicadores da população em geral, possivelmente, durante a pandemia, professores estão com os mesmos sintomas diante de todas as alterações impostas ao seu modo de vida e a sua prática docente.

Além disso, uma contribuição psicanalítica sugere pensar o isolamento social como algo que pode influenciar nosso mundo interno de maneira negativa, mobilizando os afetos mais profundos e agitando sentimentos subjetivos relativos à sociabilidade: são as interdições dos nossos desejos. Nesse sentido, Sanches (2010) esclarece que, para a psicanálise, o desejo significa uma falta que é mediada pela linguagem e, de certa forma, internalizada pela relação com o outro, nesse caso, aluno/professor.

Concordando com esse parecer sobre o desejo e a falta, Preuss, Perotti e Schuk (2020, p. 3) asseveram que

O sujeito é um ser faltante, e isso o leva a buscar satisfações para essas faltas, ou seja, todos os desejos advêm de uma falta. Por isso, a falta na psicanálise é considerada um elemento essencial, pois é ela que leva ao desejo e a busca por realizações. O desejo é a força vital do sujeito, que impulsiona o ser humano a fazer as coisas que faz, a criação, ao novo.

Então, dessa perspectiva, tem-se um contraponto entre a questão do desejo e as práticas docentes na pandemia. Por um lado, os professores tiveram que aprender a lidar com tecnologias, aplicativos e ferramentas antes não utilizados em sala de aula e, dessa forma, muitos professores, demonstraram, pela força vital de aprendizagem e reinvenção, o impulsionamento para o novo. Por outro lado, temos as questões do desejo que foram vivenciadas pelas interdições, castrações e pela repressão impostas, que podem ser relacionadas à falta da liberdade, do ir e vir, e à falta do espaço escolar, da convivência presencial com alunos e suas respectivas famílias.

Cabe, aqui, ressaltar o conceito de castração proposto pela psicanálise, visto que não se tratar do procedimento cirúrgico de extirpação dos órgãos genitais masculinos, mas, sim, da representação de um movimento dinâmico mental de aceitação da quebra da onipotência do eu, relacionada ao processo imaginativo da relação com o outro (SANCHES, 2010). Diante disso, o isolamento social e a quarentena trouxeram à tona sentimentos de castração no que diz respeito aos indivíduos vivenciarem que não estão no controle das situações e da vida. Sanches (2010) ainda explica que a repressão pode ser considerada um mecanismo de defesa que atua a partir do 
cerceamento imposto pela sociedade, a exemplo, nesse caso, do fato de "não poder ir à escola", não poder socializar com parentes e amigos", "não poder receber visitas".

Em decorrência dessa reflexão sobre os aspectos da castração e da repressão na vivência do professor durante a pandemia, é possível pensar que tais experiências podem adquirir uma forma individual de angústia - como, por exemplo, a angústia de castração - e os sintomas resultantes dessa situação são a base das expressões dos sintomas neuróticos. De acordo com Preuss, Perotti e Schuk (2020), medos, fobias e sintomas diversos que surgem no plano consciente são efeitos de conflitos nas tentativas de defesa contra a emergência dessa angústia, que parece insuportável.

Sendo assim, vemos que tais sintomas não se apresentam apenas por questões físicas, mas convergem para o corpo e para a pele em sintomas psicossomáticos. Segundo Ávila (2002, p. 37), os sintomas psicossomáticos manifestam-se como um processo subjetivo que pode ser realizado por meio do corpo, ou seja, o processo somático ocupa o espaço da ordem psicológica, porém revela-se na pele e no corpo.

Concomitantemente às adaptações pedagógicas feitas pelos educadores nesse momento, temos as questões de saúde mental e física que envolvem os indivíduos e a sociedade e, conforme Brooks et al. (2020) e Xiao (2020), o aspecto psicológico deve ser levado em consideração no levantamento de medidas preventivas para a minimização das consequências negativas.

Na perspectiva de Diehl e Marin (2016, p. 79),

\begin{abstract}
Alguns fatores que levam ao adoecimento dos professores são comuns a todos os níveis de ensino investigados e estão relacionados à organização do trabalho, falta de reconhecimento, problemas comportamentais dos alunos, pouco acompanhamento familiar e deficiências no ambiente físico.
\end{abstract}

Murta (2001) confirma esse ponto de vista quando relata que os professores são parte de um quadro de profundas mudanças sociais, situação que corresponde a mudanças não menos profundas na Educação e no desempenho exigido da profissão docente. Em suas palavras,

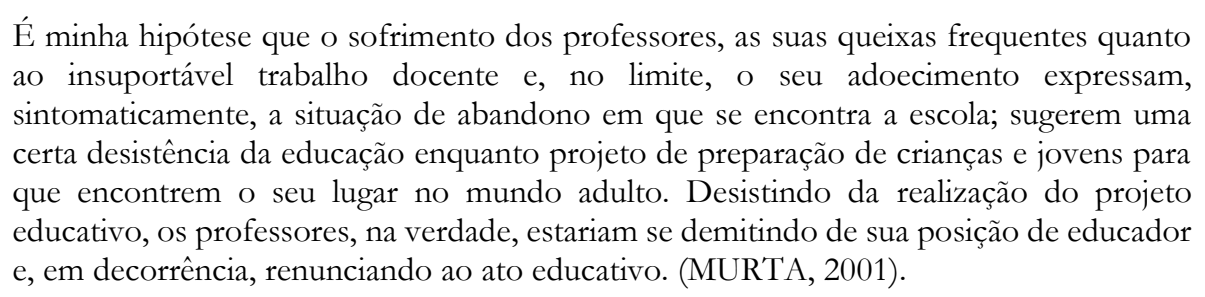

A autora ainda diz que 
Se não cabe propor uma psicanálise coletiva dos professores na escola, cabe sim alertar para a necessidade que as pessoas têm de ser ao menos escutadas em seu trabalho. É preciso que um espaço de escuta seja criado na escola, para que os seus profissionais pessoas responsáveis pela formação de outras pessoas - possam, ao serem ouvidos, ouvir a si mesmos. (MURTA, 2001).

Com efeito, a pandemia causada pela COVID-19 fez com que as mudanças sociais fossem aceleradas, as adaptações das práticas pedagógicas alteradas com certa urgência e, assim como os sentimentos de castração e repressão, e o mal-estar docente mostrou-se presente na realidade brasileira.

\section{Considerações finais}

A Educação se reinventou, se transformou, se adaptou no ano de 2020 e tais alterações podem ser consistentes se o olhar sobre as pessoas que a fazem acontecer for diferente. Baseados nos escritos de Mannoni (1980) construímos uma indagação pertinente à reflexão deste trabalho: se o sintoma pode ser fruto de certo tipo de sofrimento e angústia, o que é que, apesar de não serem verbalizados, o sintoma e o mal-estar docente nos revelam?

Como foi observado em alguns aspectos deste trabalho, pesquisas de diferentes áreas do conhecimento investigam a saúde do professor, indicando que este papel profissional e social tem relevância em nossa sociedade. Se tais pesquisas e levantamentos foram feitos antes da chegada da COVID-19, é possível que, com as reinvenções da Educação e dos educadores, alguns sintomas físicos, comportamentais, emocionais e cognitivos estarão mais presentes no cotidiano docente.

Desse modo, será importante retomar o que diz Françoise Dolto (1980, p. 12): “o que importa não são os sintomas [...], mas o que significa, para aquele que vive, exprimindo tal ou qual comportamento". Pelo olhar psicanalítico, a expressão, a fala e a escuta são importantes na simbolização dos sintomas e, confirmando tal possibilidade, mesmo que inacabada, vem a relevância do ouvir os professores e suas ansiedades, deixá-los falar sobre o que sofrem e como sofrem. Muitas vezes, podem não se reconhecer na própria fala, mesmo que o sofrimento de que reclamam não seja julgado por eles, mesmo que não tenham a percepção total da produção desse sofrimento.

Sendo assim, é importante considerar que educação e saúde são condições essenciais para o desenvolvimento do ser humano e, nesse processo, os professores são peças fundamentais e devem ser valorizados como tal. Diante dos problemas e das necessidades atuais, esses profissionais precisam ter habilidades técnicas, sociais e emocionais, além de estimular a construção crítica pessoal para que aprendam a ser conscientes, reflexivos e participativos, sem deixar de lado a saúde mental e emocional. 


\section{Referências}

ANDRADE, Patrícia Santos de; CARDOSO, Telma Abdalla de Oliveira. Prazer e dor na docência: revisão bibliográfica sobre a Síndrome de Burnout. Saude e sociedade, São Paulo, v. 21, n. 1, p. 129-140, Mar. 2012. Disponível em: http://www.scielo.br/pdf/sausoc/v21n1/13.pdf. Acesso em: 03 Set. 2020.

ARAÚJO, Francisco Jonathan de Oliveira et al. Impact Of Sars-Cov-2 And Its Reverberation In Global Higher Education And Mental Health. Psychiatry Research, vol. 288 (2020): 112977.

Disponível em: https://www.sciencedirect.com/science/article/abs/pii/S0165178120307009. Acesso em: 13 set. 2020.

ASMUNDSON, Gordon J. G.; TAYLOR, Steven. Coronaphobia: Fear and the 2019-nCoV outbreak. Journal of Anxiety Disorders, 70, 102196. 2020. Disponível em: https://pubmed.ncbi.nlm.nih.gov/32078967/. Acesso em: 18 set. 2020.

ÁVILA, Lazslo Antonio. Doenças do corpo e doenças da alma: investigação psicossomática psicanalítica. São Paulo: Escuta. 2002.

BROOKS, Samantha K. et al. The psychological impact of quarantine and how to reduce it: Rapid review of the evidence. The Lancet, v. 395, p. 912-920. 2020. Disponível em: https://www.thelancet.com/action/showPde?pii=S0140-6736\%2820\%2930460-8. Acesso em: 20 set. 2020 .

CARVALHO, Mônica de Aguiar; VASQUES, Letícia Veiga. A contribuição do conceito da transferência no saber docente aplicada à sua relação com o aluno do ensino fundamental I. In: $9^{\circ}$ Congresso Pós-Graduação UNIS. 2016, Varginha - MG. Anais eletrônicos, Varginha: Fundação de Ensino e Pesquisa do Sul de Minas, p. 1-14, 2016. Disponível em:

http://repositorio.unis.edu.br/handle/prefix/426. Acesso em: 10 set. 2020.

CARVALHO, Poliana Moreira de Medeiros et al. The psychiatric impact of the novel coronavirus outbreak. Psychiatry Research, 286, 112902. 2020. Disponível em:

https://pubmed.ncbi.nlm.nih.gov/32146248/. Acesso em: 21 set. 2020.

DIEHL, Liciane; MARIN, Angela Helena. Adoecimento mental em professores brasileiros: revisão sistemática da literatura. Estudos Interdisciplinares em Psicologia, Londrina, v. 7, n. 2, p. 64-85, dez. 2016. Disponível em: http://pepsic.bvsalud.org/pdf/eip/v7n2/a05.pdf. Acesso em: 04 set. 2020.

DOLTO, Françoise. Prefácio. In: MANNONI, Maud. A primeira entrevista em psicanálise. Rio de Janeiro: Campus. 1980

ESTEVE, José Manuel. Mudanças Sociais e a função docente. Lisboa, Portugal: Porto Editora. 1995.

ESTEVE, José Manuel. O mal-estar docente: a sala de aula e a saúde dos professores. Bauru, SP: EDUSC. 1999.

FILLOUX, Jean-Claude. Psicanálise e educação. São Paulo: Expressão e Arte. 2002. 


\section{Dialogia}

PACHIEGA, Michel Douglas; MILANI, Débora Raquel da Costa. Pandemia, as reinvenções educacionais e o mal-estar docente: uma contribuição sob a ótica psicanalítica

FREUD, Sigmund. Algumas reflexões sobre a psicologia do escolar. Obras Psicológicas Completas de Sigmund Freud, v. 13. Rio de Janeiro: Imago. 1969. (Trabalho original publicado em 1914).

FREUD, Sigmund. O mal-estar na civilização. Edição Standard Brasileira das Obras Psicológicas Completas de Sigmund Freud, v. 21. Rio de Janeiro: Imago. 1996. (Trabalho original publicado em 1930).

REUD, Sigmund. Moral sexual civilizada. Edição Standard Brasileira das Obras Psicológicas Completas de Sigmund Freud, v. 9. Rio de Janeiro: Imago. 1976a (Originalmente publicado em 1908).

FREUD, Sigmund. Explicações, aplicações e orientações. Edição Standard Brasileira das Obras Psicológicas Completas de Sigmund Freud, v. 22. Rio de Janeiro: Imago. 1976b (Originalmente publicado em 1932).

FREUD, Sigmund. Análise terminável e interminável. Edição Standard Brasileira das Obras Psicológicas Completas de Sigmund Freud, v. 23. Rio de Janeiro: Imago. 1976c (Originalmente publicado em 1937).

GRANDISOLI, Edson; JACOBI, Pedro Roberto; MARCHINI, Silvio. Pesquisa Educação, Docência e a COVID-19. São Paulo: USP, 2020. Disponível em: http://www.iea.usp.br/pesquisa/projetosinstitucionais/usp-cidades-globais/pesquisa-educacao-docencia-e-a-covid-19. Acesso em: 15 set. 2020.

KUPFER, Maria Cristina Machado. Freud e a educação o mestre do impossivel. São Paulo: Scipione Editora, 2005.

LACAN, Jacques. O seminário - Livro 8: a transferência. Rio de Janeiro: Jorge Zahar Editor, 1992 [1960-1961].

LACAN, Jacques. O seminário - Livro 11: Os quatro conceitos da psicanálise. Rio de Janeiro: Jorge Zahar Editor, 1988 [1964].

LAMEIRA, Valéria Maia; COSTA, Márcio Clayton da Silva; RODRIGUES, Simone de Miranda. Fundamentos Metodológicos da Pesquisa Teórica em Psicanálise. Revista Subjetividades, [S.L.], v. 17, n. 1, p. 68-78, 23 ago. 2017.

MALDONADO, Alberto Efendy. Pesquisa em comunicação: trilhas históricas, contextualização, pesquisa empírica e pesquisa teórica. In: MALDONADO, Alberto Efendy. Metodologias de Pesquisa em Comunicação. Porto Alegre: Sulina, 2011.p. 279-303.

MANNONI, Maud. A primeira entrevista em psicanálise. Rio de Janeiro: Campus. 1980.

MIRANDA, Margarete Parreira; VASCONCELOS, Renata Nune; SANTIAGO, Ana Lydia Bezerra. Pesquisa em psicanálise e educação: a conversação como metodologia de pesquisa. In: Psicanálise, Educação e Transmissão, São Paulo, v. 6, 2006. Disponível em:

http://www.proceedings.scielo.br/scielo.php?script=sci_arttext\&pid=MSC000000003200600010 0060\&lng=en\&nrm=abn. Acesso em: 12 set. 2020. 


\section{Dialogia}

PACHIEGA, Michel Douglas; MILANI, Débora Raquel da Costa. Pandemia, as reinvenções educacionais e o mal-estar docente: uma contribuição sob a ótica psicanalítica

MURTA, Cláudia. Magistério e sofrimento psíquico: contribuição para uma leitura psicanalítica da escola.. In: Anais do Colóquio do LEPSI IP/FE-USP, São Paulo, v. 3, 2001. Disponível em: http://www.proceedings.scielo.br/scielo.php?pid=MSC0000000032001000300031\&script=sci_a rttext. Acesso em: 05 set. 2020.

OMS - Organização Mundial de Saúde. OMS afirma que COVID-19 é agora caracterizada como pandemia. 2020. Disponível em:

https:/ / www.paho.org/bra/index.php?option=com_content\&view=article\&id=6120:omsafirma-que-covid-19-e-agora-caracterizada-como-pandemia\&Itemid=812. Acesso em: 14 set. 2020.

PREUSS, Fernanda Carina; PEROTTI, Eduardo Diego; LUIS SCHUK, Anderson Luis. E como ficam nossos desejos? Um olhar psicanalítico sobre a pandemia do covid-19. Anuário Pesquisa e Extensão Unoesc. São Miguel do Oeste, v. 5, p. 1-13. 2020. Disponível em: https://core.ac.uk/download/pdf/327185511.pdf. Acesso em: 20 set. 2020.

RIBEIRO, Márden de Pádua. Contribuição da psicanálise para a educação: a transferência na relação professor/aluno. Psicologia da Educação, São Paulo, n. 39, p. 23-30, dez. 2014 . Disponível em: http://pepsic.bvsalud.org/pdf/psie/n39/n39a03.pdf. Acesso em: 13 set. 2020.

RIBEIRO, Mariane Vieira Machado. A educação e a psicanálise: um encontro possível? Psicologia: Teoria e Prática, v. 8, n. 2, p. 112-122, 2006. Brasília. Disponível em:

http://pepsic.bvsalud.org/pdf/ptp/v8n2/v8n2a08.pdf. Acesso em: 15 set. 2020.

SANCHES, Pedro. A alteridade na conceituação freudiana de desejo e pulsão. São Paulo, 2010. Revista Brasileira de psicanálise [online]. 2010, v. 44, n. 4. Disponível em: http://pepsic.bvsalud.org/pdf/rbp/v44n4/a09.pdf. Acesso em: 10 set. 2020.

SANTOS, Jacia Maria Soares dos. A transferência no processo pedagógico: quando fenômenos subjetivos interferem na relação de ensino-aprendizagem. 2009. Dissertação (Mestrado no Programa de Pósgraduação em Educação Conhecimento e Inclusão Social). Faculdade de Educação da Universidade Federal de Minas Gerais, Belo Horizonte. Disponível em: https://repositorio.ufmg.br/bitstream/1843/FAEC-84GTXZ/1/disserta_o_jacia.pdf. Acesso em: 04 Set. 2020.

SILVA, Andrey Ferreira da et al . Saúde mental de docentes universitários em tempos de pandemia. Physis, Rio de Janeiro, v. 30, n. 2, e300216, 2020 . Disponível em:

http://www.scielo.br/pdf/physis/v30n2/0103-7331-physis-30-02-e300216.pdf. Acesso em: 04 Set. 2020.

SOUZA, Aparecida Neri de; LEITE, Marcia de Paula. Condições de trabalho e suas repercussões na saúde dos professores da educação básica no Brasil. Educação \& Sociedade, Campinas, v. 32, n. 117, p. 1105-1121, Dez. 2011 . Disponível em:

http://www.scielo.br/pdf/es/v32n117/v32n117a12.pdf. Acesso em: 18 Set. 2020.

TOSTES, Maiza Vaz et al. Sofrimento mental de professores do ensino público. Saúde em debate, Rio de Janeiro, v. 42, n. 116, p. 87-99, Jan. 2018. Disponível em: http://www.scielo.br/pdf/sdeb/v42n116/0103-1104-sdeb-42-116-0087. pdf. Acesso em: 04 Set. 2020 . 
UNESCO. A Comissão Futuros da Educação da Unesco apela ao planejamento antecipado contra o aumento das desigualdades após a COVID-19. Paris: Unesco, 16 abr. 2020. Disponível em:

https://pt.unesco.org/news/comissao-futuros-da-educacao-da-unesco-apela-ao-planejamentoantecipado-o-aumento-das. Acesso em: 4 set. 2020.

VASCONCELOS, Renata Nunes; MIRANDA, Margarete Parreira. Psicanálise, educação e o mal estar na formação de professores. In: Proceedings online. Retratos do mal-estar comtemporaneo na educação, São Paulo: FE/USP, v. 9, 2012. Disponível em:

http://www.proceedings.scielo.br/pdf/lepsi/n9/a48n9.pdf. Acesso em: 05 set. 2020.

WANG, Cuiyan et al. Immediate Psychological Responses and Associated Factors during the Initial Stage of the 2019 Coronavirus Disease (COVID-19) Epidemic among the General Population in China. International journal of environmental research and public health v. 17, n. 5, 6 Mar. 2020. Disponível em https://pubmed.ncbi.nlm.nih.gov/32155789/. Acesso em: 19 set. 2020.

XIAO, Chunfeng. A novel approach of consultation on 2019 novel coronavirus (COVID-19)related psychological and mental problems: Structured letter therapy. Psychiatry Investigation, v. 17, n. 2, p. 175-176, 2020. Disponível em: https:// doi.org/10.30773/pi.2020.0047. Acesso em: 20 set. 2020.

Recebido em: 30 set. 2020/ Aprovado em: 07 dez. 2020

Cite como

(ABNT NBR 6023:2018)

PACHIEGA, Michel Douglas; MILANI, Débora Raquel da Costa. Pandemia, as reinvenções educacionais e o mal-estar docente: uma contribuição sob a ótica psicanalítica. Dialogia, São Paulo, n. 36, p. 220-234, set./dez. 2020. Disponível em:

https://doi.org/10.5585/dialogia.n36.18323.

\section{American Psychological Association (APA)}

Pachiega, M. D., \& Milani, D. R. C. (2020, set./dez.). Pandemia, as reinvenções educacionais e o mal-estar docente: uma contribuição sob a ótica psicanalítica. Dialogia, São Paulo, 36, p. 220 234. https://doi.org/10.5585/dialogia.n36.18323. 